\title{
ADUBAÇÃO ORGÂNICA NA PRODUÇÃO E QUALIDADE DE FRUTOS DE MARACUJÁ-DOCE ${ }^{1}$
}

\author{
ERVAL RAFAEL DAMATTO JUNIOR ${ }^{2}$, SARITA LEONEL ${ }^{3}$, CARLOS JORGE PEDROSO ${ }^{4}$
}

\begin{abstract}
RESUMO - Avaliaram-se os efeitos da adubação orgânica no desenvolvimento, na produção e na qualidade de frutos do maracujazeiro-doce (Passiflora alata Dryand). Como adubo orgânico, utilizou-se do esterco de curral curtido nas proporções de 50\%, 100\%, 150\% e 200\% da dosagem recomendada para a cultura), além da testemunha. O experimento foi conduzido em Botucatu-SP, num Nitossolo Vermelho. Avaliaram-se o comprimento e o diâmetro dos ramos, o número, o diâmetro e a massa dos frutos por planta, o rendimento de polpa, o pH, a acidez ( $\mathrm{g}$ ácido cítrico/100g de fruto), o teor de sólidos solúveis totais ( ${ }^{\circ}$ Brix) e a relação SST/ATT ("Ratio"). Os melhores resultados foram obtidos na dosagem de $100 \%$ (5kg de esterco planta $\left.^{-1}\right)$. Neste tratamento, verificou-se melhor qualidade, maior número de frutos e maior produção por planta.
\end{abstract}

Termos para indexação: adubação orgânica, nitrogênio, Passiflora alata (Dryand), produção, irrigação, pós-colheita.

\section{ORGANIC FERTILIZATION IN FRUIT PRODUCTION AND QUALITY OF SWEET PASSION FRUIT}

\begin{abstract}
It was evaluated the effects of the organic fertilization in development, production and fruits quality of sweet passion fruit (Passiflora alata Dryand). As an organic fertilizer, it was used cattle manure (50\%, 100\%, 150\% and 200\% of the recommended dose for the culture) and the control treatment. The experiment was conduced in Botucatu/SP, in a Red Nitosoil. It was evaluated length and diameter of the branches, number of fruits, fruits diameter, fruits weigh, pulp production, $\mathrm{pH}$, acidity (g citric acid/100g of fruit), total soluble solids ( ${ }^{\circ}$ Brix) and the relation SST/ATT ("Ratio"). The best results were obtained with the dose of $100 \%$ ( $5 \mathrm{~kg}$ of cattle manure plant $\mathrm{t}^{-1}$. This treatment showed better quality, larger number of fruits and larger production.
\end{abstract}

Index terms: organic fertilization, nitrogen, Passiflora alata (Dryand), production, irrigation, post-harvest.

O maracujá-doce (Passiflora alata Dryand), conhecido popularmente por maracujá de refresco, maracujá de comer, maracujá-alado, maracujá-guaçu, é uma trepadeira que apresenta o caule quadrangular e frutos ovais a piriformes, amarelos ou laranja, comestíveis e adocicados, com polpa muito perfumada e ligeiramente ácida. Provavelmente, é originário do Brasil, onde está distribuído pelos Estados da Bahia, Mato Grosso, Minas Gerais, Rio de Janeiro, São Paulo, Paraná, Santa Catarina, Goiás, Amazonas e Pará, sendo encontrado também no Peru (Cunha \& Barbosa, 2002).

O maracujazeiro-doce é altamente produtivo, chegando a produzir, nas condições do Estado de São Paulo, até 50 toneladas por hectare. Para isso são requeridas elevadas adubações para assegurar as quantidades necessárias de nutrientes para o crescimento das plantas e alta produtividade (Kavati et al., 2002). Nesse contexto, adubações e irrigações, quando corretamente aplicadas, são práticas altamente recomendadas, por influenciar direta e positivamente na produtividade. Porém, a falta de informações sobre os níveis adequados de fertilizantes e irrigações a serem aplicados em cada condição de plantio, não têm permitido, na maioria dos casos, inferências a respeito desses insumos, o que tem prejudicado o desenvolvimento da cultura (Carvalho et al., 2000).

Sendo o maracujazeiro-doce uma planta exigente em mão-deobra, principalmente para a execução dos tratos culturais, como podas, polinização artificial, controle de plantas daninhas e controle fitossanitário, adapta-se muito bem às condições dos pequenos produtores, que empregam a mão-de-obra familiar, além de servir como alternativa de diversificação na propriedade. Outro importante aspecto relacionado à cultura é a possibilidade de maiores rendimentos ao produtor por unidade de área.

Visando a suprir a carência de informações com relação à adubação, realizou-se o presente trabalho objetivando avaliar os efeitos da adubação orgânica no desenvolvimento, na produção e na qualidade de frutos do maracujazeiro-doce (Passiflora alata Dryand).

\section{MATERIALEMÉTODOS}

O experimento foi conduzido na Faculdade de Ciências Agronômicas/UNESP, Câmpus de Botucatu-SP, que tem como coordenadas geográficas: $22^{\circ} 52^{\prime} 47^{\prime \prime}$ latitude S, 48²5' $12^{\circ}$ ' longitude W e altitude de $810 \mathrm{~m}$ (Tubelis \& Salibe, 1989).

As mudas foram produzidas com sementes extraídas de frutos maduros e transplantadas para o campo quando emitiram as primeiras gavinhas (cerca de 80 dias após a semeadura). Aárea destinada ao plantio $\left(960 \mathrm{~m}^{2}\right)$ apresenta um solo classificado como Nitossolo Vermelho (Embrapa, 1999), o qual foi arado e gradeado, seguindo-se de calagem em área total, com calcário dolomítico, visando-se a elevar a saturação por bases a 80\% (Piza Júnior et al., 1997). O plantio no campo foi realizado em janeiro de 2002, adotando-se sistema de condução em latada, com espaçamento de $2 \mathrm{~m}$ entre linhas e $4 \mathrm{~m}$ entre plantas $\left(8 \mathrm{~m}^{2}\right.$ planta $\left.^{-1}\right)$, proporcionando um estande de 1.250 plantas ha-1.

TABELA 1 - Resultados de análise química do esterco utilizado na adubação do maracujazeiro-doce.

\begin{tabular}{ccccccccc}
\hline \multicolumn{10}{c}{ Resultado em porcentagem na matéria seca } \\
\hline $\mathbf{N}$ & $\mathbf{P}_{\mathbf{2}} \mathbf{O}_{\mathbf{5}}$ & $\mathbf{K}_{\mathbf{2}} \mathbf{O}$ & $\mathbf{U m} \%$ & $\mathbf{M O}$ & $\mathbf{C}$ & $\mathbf{C a}$ & $\mathbf{M g}$ & $\mathbf{S}$ \\
\hline 1,25 & 1,52 & 1,68 & 41,00 & 43,00 & 23,89 & 1,50 & 0,50 & 0,18 \\
\hline \multicolumn{10}{c}{ Resultado em $\mathrm{mg} / \mathrm{kg}$ na matéria seca } \\
\hline $\mathbf{1 0}$ & $\mathbf{C u}$ & $\mathbf{M n}$ & $\mathbf{N a}$ & $\mathbf{Z n}$ & $\mathbf{p H}$ & $\mathbf{C} / \mathbf{N}$ \\
\hline $\mathbf{F e}$ & $\mathbf{C u}$ & 120 & 146 & - & 190 & 7,60 & $19 / 1$ \\
\hline
\end{tabular}

Fonte: Laboratório de Análises de Fertilizantes e Corretivos. DCS-FCA.

Empregaram-se, na segunda safra, os tratamentos com doses de esterco de curral curtido (Tabela 1), os quais foram definidos conforme resultados da análise de solo (Tabela 2) e de acordo com a tabela de recomendação para maracujazeiro (Piza Júnior et al., 1997), sendo os mesmos parcelados em duas aplicações: $\mathrm{T} 1=$ Testemunha $(0 \%$ de adubo orgânico): adubação química convencional recomendada para a cultura

\footnotetext{
${ }^{1}$ (Trabalho 157/2004). Recebido: 12/11/2004. Aceito para publicação: 19/04/2005.

${ }^{2}$ Eng $^{\circ}$ Agr $^{\circ}$. Mestrando em Energia na Agricultura/FCA/UNESP. Cx postal: 237, Cep: 18603-970. Botucatu-SP. Fone: (14) 3811-7169. Endereço eletrônico: ervaljr@ig.com.br;

${ }^{3}$ Prof $^{a}$ Assistente Dra . Departamento de Produção Vegetal/FCA/UNESP. Cx postal: 237, Cep: 18603-970. Botucatu-SP. Fone: (14) 3811-7172. Endereço eletrônico: sarinel@fca.unesp.br;

${ }^{4}$ Técnico Agropecuário. Bolsista da Fapesp.
} 
TABELA 2 - Análise química inicial do solo da área experimental, na profundidade de $0-20 \mathrm{~cm}$.

\begin{tabular}{|c|c|c|c|c|c|c|c|c|c|}
\hline $\begin{array}{c}\mathrm{pH} \\
\mathrm{CaCl}_{2}\end{array}$ & $\begin{array}{l}\text { M.O. } \\
\text { g/dm }\end{array}$ & $\begin{array}{l}P \text { resina } \\
\mathrm{mg} / \mathrm{dm}^{3}\end{array}$ & $\mathbf{H}+\mathbf{A l}$ & $\mathbf{K}$ & $\mathrm{Ca}$ & $\begin{array}{l}\mathrm{Mg} \\
\mathrm{dm}^{3}\end{array}$ & SB & CTC & $\begin{array}{c}V \\
(\%)\end{array}$ \\
\hline 5,4 & 19 & 21 & 22 & 3,2 & 40 & 9 & 52 & 74 & 32 \\
\hline
\end{tabular}

Fonte: Laboratório de Fertilidade do Solo. DCS-FCA.

(400g de sulfato de amônio/planta); $\mathrm{T} 2=50 \%$ da dosagem recomendada de $\mathrm{N}(2,5 \mathrm{~kg}$ de esterco $=40 \mathrm{~g} \mathrm{~N} /$ planta $) ; \mathrm{T} 3=100 \%$ da dosagem recomendada de $\mathrm{N}(5,0 \mathrm{~kg}$ de esterco $=80 \mathrm{~g} \mathrm{~N} /$ planta $) ; \mathrm{T} 4=150 \%$ da dosagem recomendada de $\mathrm{N}(7,5 \mathrm{~kg}$ de esterco $=120 \mathrm{~g} \mathrm{~N} /$ planta $) ; \mathrm{T} 5=$ $200 \%$ da dosagem recomendada de $\mathrm{N}(10,0 \mathrm{~kg}$ de esterco $=160 \mathrm{~g} \mathrm{~N} /$ planta $)$, sendo que em todos os tratamentos se aplicaram nas covas de plantio $200 \mathrm{~g}$ de termosfosfato $+137 \mathrm{~g}$ de cloreto de potássio $+2,16 \mathrm{~kg}$ de calcário/ planta.

Instalou-se um sistema de irrigação por gotejo, localizado sob a copa, com freqüência de 3 horas diárias, numa vazão de 2,64 litros/ hora, sendo empregada quantidade uniforme para todas as plantas, exceto em dias chuvosos. No decorrer do experimento, foram realizados outros tratos culturais, tais como: controle mecânico de plantas daninhas, desbrotas, polinização artificial e controle fitossanitário, principalmente contra a bacteriose, que ocorreu com freqüência, para a qual, preventivamente, foi aplicada semanalmente calda bordaleza, além de uma aplicação de "Agrimicina" + Cobre.

Na segunda safra (maio de 2003), avaliaram-se a produção das plantas e as características qualitativas dos frutos. Os parâmetros avaliados foram: comprimento médio dos ramos primários (m), diâmetro médio de ramos primários a $20 \mathrm{~cm}$ do solo, secundários e terciários a $20 \mathrm{~cm}(\mathrm{~mm})$, número médio de frutos por planta; diâmetro $(\mathrm{cm})$ e peso médio dos frutos $(\mathrm{kg})$, além do rendimento de polpa, $\mathrm{pH}$, acidez (g ácido cítrico/100g de fruto), teor de sólidos solúveis totais (SST - ${ }^{\circ}$ Brix) e a relação SST/ATT ("Ratio").

O delineamento estatístico empregado para os dados fitotécnicos foi inteiramente casualizado, com 5 tratamentos, 3 repetições e 2 plantas úteis por parcela experimental, enquanto para as análises laboratoriais foram mantidos os 5 tratamentos de campo, com 5 repetições e 3 frutos por parcela. Os tratamentos corresponderam às dosagens de esterco de curral curtido e tiveram seus efeitos avaliados pelo teste de comparação de médias de Tukey, ao nível de 5\% de probabilidade e por regressão polinomial (Kronka \& Banzatto, 1992).

\section{RESULTADOSE DISCUSSÃO}

Verificaram-se para massa e diâmetro de frutos, altura de plantas e diâmetro de ramos primários, secundários e terciários, os seguintes valores: $205,67 \pm 48,51 \mathrm{~g} ; 7,09 \pm 0,25 \mathrm{~cm} ; 2,03 \pm 0,07 \mathrm{~m} ; 24,20 \pm 2,77 \mathrm{~mm}$; $17,88 \pm 3,16 \mathrm{~mm} ; \mathrm{e} 10,97 \pm 1,97 \mathrm{~mm}$, respectivamente. Neste experimento, a massa e o diâmetro dos frutos foram inferiores aos encontrados por Vasconcellos et al. (1993), porém a massa dos frutos está de acordo com os valores citados por Oliveira et al. (1982), onde os frutos de maracujádoce apresentam peso que varia de 80 a $300 \mathrm{~g}$.

No T3 (80g N/planta), observou-se maior número de frutos por planta $(74,17)$, diferindo significativamente dos demais, possivelmente devido a uma nutrição mais adequada e balanceada às plantas. Como pode ser observado na Figura 1, o número de frutos aumentou conforme foi elevada a dose de esterco até atingir o máximo com $80 \mathrm{~g} \mathrm{~N} /$ planta (T3).
A partir daí, doses maiores não geraram incrementos devido à maior vegetação das plantas; desta forma, o excesso de esterco (nutrientes) estimulou mais a planta a vegetar do que a produzir.

A maior produção (15,94 kg/planta) foi encontrada em plantas adubadas com a dose de $100 \%$ de adubo orgânico (80g N/planta) Figura 2. Essa maior produção pode estar relacionada a um adequado fornecimento e disponibilidade de nutrientes fornecidos pela adubação orgânica, visto que doses maiores não proporcionaram incrementos em produção. Já a mesma dose de adubação convencional (T1) não apresentou bons resultados $(9,50 \mathrm{~kg} / \mathrm{planta})$, e isto pode estar relacionado à melhoria nas condições físicas e químicas de solo proporcionada pela adubação orgânica, que também ajuda a manter a umidade no solo.

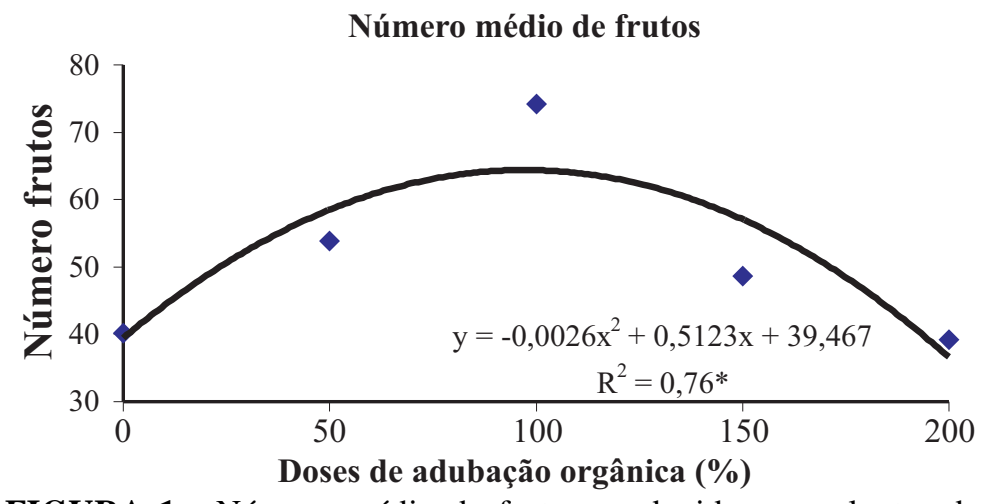

FIGURA 1 - Número médio de frutos produzidos por plantas de maracujazeiro-doce adubados com diferentes doses de esterco.

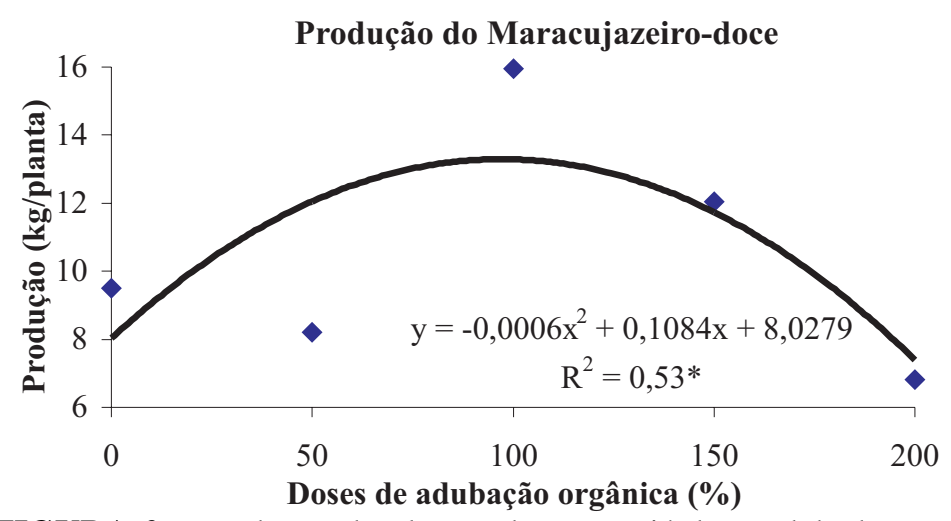

FIGURA 2 - Produção de plantas de maracujá-doce adubadas com diferentes doses de esterco.

Os teores foliares de nitrogênio variaram entre 22 e $28 \mathrm{~g} / \mathrm{kg}$, com as amostras retiradas na época de botão floral na axila (Tabela 3). De acordo com citação de Piza Junior et al. (1997), os teores de nitrogênio para essa fase seriam de 33 a $43 \mathrm{~g} / \mathrm{kg}$. No entanto, trata-se de

TABELA 3 - Resultados de análise química foliar do maracujazeiro-doce.

\begin{tabular}{|c|c|c|c|c|c|c|}
\hline Tratamentos & $\mathbf{N}$ & $\mathbf{P}$ & $\mathbf{K}$ & $\mathbf{C a}$ & Mg & $\mathbf{S}$ \\
\hline $\mathrm{T} 2=50 \%$ adubação orgânica & 25 & 1,8 & 19 & 24 & 3,3 & 2,4 \\
\hline T4= $150 \%$ adubação orgânica & 24 & 1,8 & 25 & 16 & 3,0 & 2,6 \\
\hline T5=200\% adubação orgânica & 22 & 1,9 & 18 & 19 & 3,8 & 2,9 \\
\hline
\end{tabular}


TABELA 4 - Valores médios de rendimento de polpa, pH, acidez, sólidos solúveis e ratio de frutos de maracujá-doce produzidos com diferentes doses de adubação orgânica.

\begin{tabular}{ccccc}
\hline Tratamentos & Rendimento de Polpa & pH & Acidez (g/100g) & SST/AAT (ratio) \\
\hline T1 $=\quad 0 \%$ adubação orgânica & $73,02 \mathrm{~A}$ & $3,81 \mathrm{~A}$ & $1,95 \mathrm{D}$ & $10,90 \mathrm{~A}$ \\
$\mathrm{~T} 2=50 \%$ adubação orgânica & $58,30 \mathrm{~B}$ & $3,81 \mathrm{~A}$ & $2,33 \mathrm{~B}$ & $9,06 \mathrm{BC}$ \\
$\mathrm{T} 3=100 \%$ adubação orgânica & $67,67 \mathrm{AB}$ & $3,82 \mathrm{~A}$ & $2,08 \mathrm{CD}$ & $9,79 \mathrm{ABC}$ \\
$\mathrm{T} 4=150 \%$ adubação orgânica & $74,32 \mathrm{~A}$ & $3,75 \mathrm{~A}$ & $2,51 \mathrm{~A}$ & $8,60 \mathrm{C}$ \\
$\mathrm{T} 5=200 \%$ adubação orgânica & $62,69 \mathrm{AB}$ & $3,81 \mathrm{~A}$ & $2,16 \mathrm{C}$ & $10,62 \mathrm{AB}$ \\
\hline Médias & 67,20 & 3,80 & 2,21 & 9,79 \\
\hline CV $\mathbf{( \% )}$ & 11,14 & 1,99 & 3,58 & 8,42 \\
\hline
\end{tabular}

Médias seguidas de letras distintas na mesma coluna diferem entre si, pelo teste de Tukey, a 5\%.

recomendação para maracujazeiro-azedo (Passiflora edulis Sims f. flavicarpa Deg), espécie diferente da abordada no presente trabalho. Além disso, envolve estudo de adubação química, sendo que, no presente trabalho, estão sendo estudados efeitos da adubação orgânica, e de acordo com a Comissão de Fertilidade do Solo do Estado de Minas Gerais (1989), a conversão do nitrogênio da forma orgânica para a mineral ocorre $50 \%$ no primeiro ano, $20 \%$ no segundo ano e $30 \%$ após o segundo ano. Contudo, o uso de adubação orgânica não prejudicou a produção do maracujazeiro-doce. Com relação aos demais nutrientes, (Tabela 3)de modo geral, estes encontram-se em níveis adequados, adotando-se como referência os valores citados por Piza Junior et al. (1997).

Os tratamentos aplicados no campo (doses de adubação orgânica) influenciaram significativamente na qualidade pós-colheita dos frutos. As plantas adubadas com a menor dose de adubo (T2 $=40 \mathrm{~g} \mathrm{~N} /$ planta) apresentaram menor rendimento de polpa, enquanto doses maiores $(\mathrm{T} 1=$ adubação convencional e o $\mathrm{T} 4=120 \mathrm{~g} \mathrm{~N} /$ planta $)$ apresentaram maior rendimento de polpa, sendo os valores médios apresentados na Tabela 4.

Os valores médios de $\mathrm{pH}$ não diferiram entre si para os diferentes tratamentos, (Tabela 4) apresentando a média geral o valor de 3,80 $\pm 0,08$. Valores esses um pouco superiores aos citados por Oliveira et al. (1982), que determinaram $\mathrm{pH}$ de 3,0 para frutos maduros.

Os teores médios de sólidos solúveis determinados neste trabalho são superiores aos encontrados por Oliveira et al. (1982) e Vasconcellos et al. (1993), sendo que os maiores teores foram encontrados no $\mathrm{T} 5$, onde houve maior disponibilidade de nutrientes aos frutos, enquanto os menores teores foram encontrados no T3; ou seja, com a maior dose de adubação (T5 = 160g N/planta), os frutos tiveram maior acúmulo de açúcares, enquanto com uma dose menor (T3 $=80 \mathrm{~g} \mathrm{~N} /$ planta), o acúmulo foi menor, estando os valores médios apresentados na Figura 3.

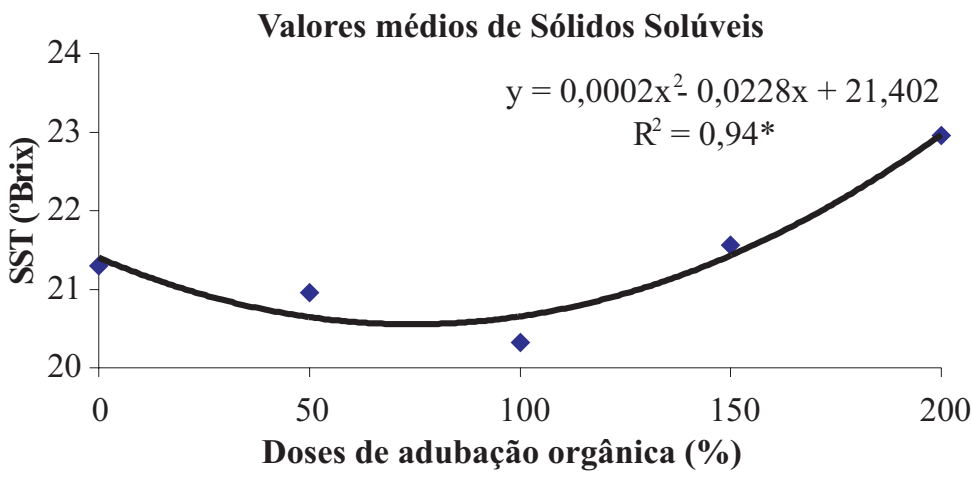

FIGURA 3 - Valores médios de sólidos solúveis totais de frutos de maracujazeiro-doce produzidos com diferentes doses de adubação orgânica.

A adubação orgânica influenciou negativamente na acidez dos frutos, uma vez que, nos tratamentos com esterco, a acidez foi mais elevada, enquanto no tratamento com adubação convencional (T1), a acidez foi menor, diferindo significativamente dos demais tratamentos (Tabela 4). A relação SST/ATT ("Ratio") apresentou diferença significativa entre os tratamentos, sendo os maiores valores encontrados no T1, enquanto em T4, os valores médios foram menores.

Com os dados obtidos neste experimento realizado em Nitossolo Vermelho, com um estande de 1.250 plantas/ha, permite-se inferir que a adubação orgânica do maracujazeiro-doce, na dosagem de 100\% (5kg de esterco/planta), uma vez que as plantas deste tratamento (T3) apresentaram maior número de frutos e maior produtividade, além de os frutos apresentarem bom rendimento de polpa, baixa acidez e moderados valores de Brix e ratio.

\section{REFERÊNCIAS}

CARVALHO, A.J.C.; MARTINS, D.P.; MONNERAT, P.H.; BERNARDO, S.; Adubação nitrogenada e irrigação no maracujazeiro-amarelo. I. Produtividade e qualidade dos frutos. Pesquisa Agropecuária Brasileira, Brasília, v.35, n.6, 2000.

COMISSÃO DE FERTILIDADE DO SOLO DO ESTADO DE MINAS GERAIS. Recomendações para o uso de corretivos e fertilizantes em Minas Gerais, 4. aproximação. Lavras, 1989. 176p.

CUNHA, M.A.P. da; BARBOSA, L.V.; JUNQUEIRA, N.T.V. Aspectos Botânicos. In: LIMA, A. de A. Maracujá produção: aspectos técnicos. Embrapa mandioca e Fruticultura Cruz das Almas. Brasília: Embrapa Informação tecnológica, 2002. p.15-24 (Frutas do Brasil; 15).

EMBRAPA. Centro Nacional de Pesquisa de Solos. Sistema Brasileiro de Classificação de Solos. Rio de Janeiro: EMBRAPA/SOLOS, 1999. 412p.

KAVATI, R.; PIZA JÚNIOR, C. de T. A Cultura do Maracujá-Doce. Campinas: CATI, 2002. 46p. (Boletim Técnico, 244).

KRONKA, S.N.; BANZATTO, D.A. Experimentação agrícola. Jaboticabal: FUNEP, 1992. 247p.

OLIVEIRA, J.C.; RUGGIERO, C.; NAKAMURA, K.; FERREIRA, F.R. Variações observadas em frutos de Passiflora alata Ait. In: CONGRESSO OF THE AMERICAN SOCIETY OF HORTICULTURALSICIENCE, 29., CONGRESSOBRASILEIRODE OLERICULURA, 21., CONGRESSODA SOCIEDADEBRASILEIRA DE FLORICULTURA E PLANTAS ORNAMENTAIS, 2. Campinas, 1981. Proceedings... Campinas: Sociedade Brasileira de Olericultura. P. 343-345. 1982.

PIZA JUNIOR, C. de T. (Coord.). et al. Maracujá. In: RAIJ, B. van; CANTARELLA, H.; QUAGGIO, J.A.; FURLANI, A.M.C. (Ed). Recomendações de adubação e calagem para o Estado de São Paulo. 2.ed. rev. e atual. Campinas: Instituto Agronômico/Fundação IAC, 1997. 285p. (Boletim Técnico 100).

TUBELIS, A.; SALIBE, A.A. Relações entre produção de laranjeira "Hamlin" e as precipitações mensais no altiplano de Botucatu. Pesquisa agropecuária brasileira, v.23, p.801-806, 1989.

VASCONCELLOS, M.A. da S.; CEREDA, E.; ANDRADE, J.M. de B.; BRANDÃO FILHO, J.U.T. Desenvolvimento de frutos de maracujazeiro 'doce'(Passiflora alata Dryand), nas condições de Botucatu - SP. Revista Brasileira de Fruticultura, Cruz das Almas, v.15, n.1, p.153-158, 1993. 